FLORIN NEMTANU, Ph.D.

E-mail: florin.nemtanu@upb.ro

ILONA COSTEA, Ph.D.

E-mail: ilona.costea@upb.ro

CATALIN DUMITRESCU, Ph.D.

E-mail: catalincatalin9@gmail.com

Politehnica University of Bucharest

Transport Faculty,

Telematics and Electronics for Transport Dept.

Splaiul Independentei nr. 313, 060042, Bucharest, Romania
Science in Traffic and Transport Original Scientific Paper

Submitted: Nov. 12, 2014

Approved: Nov. 24, 2015

\title{
SPECTRAL ANALYSIS OF TRAFFIC FUNCTIONS IN URBAN AREAS
}

\begin{abstract}
The paper is focused on the Fourier transform application in urban traffic analysis and the use of said transform in traffic decomposition. The traffic function is defined as traffic flow generated by different categories of traffic participants. A Fourier analysis was elaborated in terms of identifying the main traffic function components, called traffic sub-functions. This paper presents the results of the method being applied in a real case situation, that is, an intersection in the city of Bucharest where the effect of a bus line was analysed. The analysis was done using different time scales, while three different traffic functions were defined to demonstrate the theoretical effect of the proposed method of analysis. An extension of the method is proposed to be applied in urban areas, especially in the areas covered by predictive traffic control.
\end{abstract}

\section{KEY WORDS}

Traffic flows; Fourier analysis; urban traffic control; traffic components;

\section{INTRODUCTION}

Nowadays, the road traffic in urban area represents a big challenge in terms of providing sufficient resources for a smooth (no traffic congestion) and clean (no pollution) road transport system. One important solution for such desiderate is to use intelligent transport system applications as an intensive method of improving the quality of road transport in urban areas. The application of ITS in urban areas has to be supported by new methods of traffic analysis in order to understand much better the structure of traffic as well as the effect of traffic measures based on ITS tools.

Traffic is not a $100 \%$ predictable process, while traffic analysis and control represent an important issue, especially in cities [1]. The approximation and estimation of the volume of traffic are possible using algorithms and new systems for data acquisition and processing [2]. In fact, it is possible to define the level of prediction related to traffic, and this level could be: real (this level is impossible to be performed by any existing system), near real (the error of estimation or prediction is near zero) and estimated (the level of error is low and the estimation is acceptable in terms of results - time, cycles, efficiency, etc.).

Urban traffic is a dynamic process which is influenced by various traffic measures performed by traffic control centres, by the strategy for traffic control of said centres, and also by the behaviour of drivers (as feedback of traffic control measures). This process could be analysed at local and regional levels and its dynamics is very important for this [3].

The proposal is an extension of the solution presented in [4] to use Fourier Transform in analysing the traffic flow and the state of traffic in urban areas. In the cited paper [4] the author demonstrated by using Fourier Transform the possibility to identify the constituent components of the daily traffic count dynamics. The results of Professor Dendrinos showed that the traffic count could be decomposed in a dominant cycle (periodical function) as well as four possible non-circadian subordinate cycles of this periodical function contained in the random component. As such, the extension proposed in this paper uses the Fourier Transform to decompose the traffic function and to extract the periodic component as well as the main components which affect the general traffic flow in urban area. One example of such components of the traffic function could be the traffic sub-function associated to a bus line or private cars running from school to office (during pick-up time for students). In this paper the example of a bus line is analysed, while the method could be applied to all components. In fact, a traffic function is a sum of different periodical and non-periodical traffic 
sub-functions (every category of vehicles generates a sub-traffic function) and the main idea of this paper is to identify the pattern of each component of the traffic function.

The traffic theory as well as the traffic models are domains with a strong mathematical support, but the analysis of the traffic components and the correlation between them are new ways to find solutions for urban transport [5].

Predictive traffic control is now the better solution for urban area, but the algorithms and the implementations have to be developed and improved. The urban context is a dynamic one and the factors and components are rapidly changing, while the effect of technical progress affects this context.

\section{THE ROLE OF TRAFFIC COMPONENTS}

Various factors can affect urban traffic and the main problem is to separate them and to determine the role of every traffic component in total traffic. The definition of the traffic function is proposed, which represents the variation of the number of vehicles/hour in a given period of time.

The traffic function could be a constant (the number of vehicles is the same in time), a periodical function or a non-periodical function (with some periodical components).

Using the Fourier transform and any other complex transforms (the case of this paper is focused on using the Fourier Transform), the problem can be translated from time to frequency or other variable with the aim of understanding better the composition of traffic functions and of predicting and correlating much better the traffic measures. In Figure 1 the third traffic function was generated by adding Gaussian random noise (that means unpredictable traffic function com- ponent) to the second traffic function displayed in the middle of the figure.

The assumption accepted is that after the application of the Fourier Transform it is possible to extract the periodical traffic function from the third traffic function and to identify this periodic component in a function with a high level of noise.

The application of this solution can also improve the efficiency of predictive traffic control schemes. Some basic algorithms are proposed in the following sections of the paper.

The Fourier analyses were applied on two different time scales: day (a 24 hours period of analysis) and week (a 7 days period of analysis) and a software tool was used to facilitate the demonstration of this hypothesis [6].

The assumption is that the traffic function component generated by buses is a periodical function (this is a first approximation) based on their schedule and this could be an example of periodic component of traffic function in urban area.

\section{METHODS AND MATHEMATICAL INSTRUMENT}

The mathematical instrument used in this paper is the Fourier transform which will be applied on the traffic function. This traffic function is the variation of vehicles number per hour on a given section/area of urban road network in a certain unit of time (this time unit could be a day, a week, a month, a season and a year).

The main instrument used is the Fourier transform and the definition of relations $[7,8]$ is as follows:

Let $f$ be a function defined on all $x \in R$ with complex value (in $C$ ) and integrable (Lebesgue integration). The Fourier transform of function $f$ is a mapping $F: R \rightarrow C$ defined by:

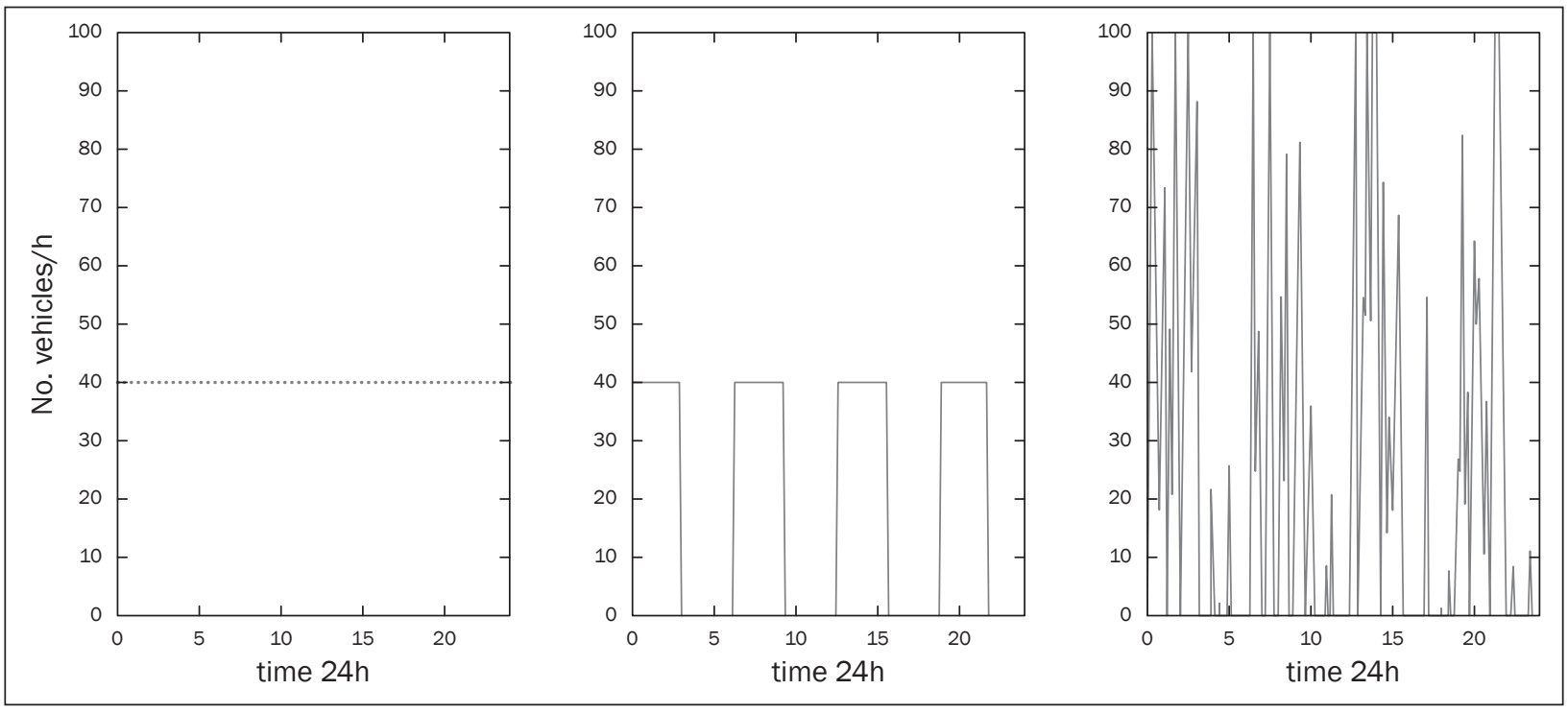

Figure 1 - Traffic functions (three cases - constant, periodic and non-periodic) 
$F(\omega)=\int_{-\infty}^{+\infty} f(x) e^{-i \omega x} d x$

and the inverse Fourier transform is defined as:

$F^{-1}(\omega)=f(x)=\int_{-\infty}^{+\infty} F(\omega) e^{i \omega x} d \omega$

In some cases it is necessary to have a discrete time scale and a discrete Fourier transform, especially for computer processing. The discrete form of the Fourier transform is defined as:

$X_{k}=\sum_{n=0}^{N-1} X_{n} e^{-\frac{i 2 \pi k n}{N}}, k \in Z$

where the sequence of $N$ complex numbers $x_{0} x_{1} \ldots x_{N-1}$ is transformed into an $N$-periodic sequence of complex numbers $X_{k}$.

The inverse transform is calculated based on the expression

$x_{n}=\frac{1}{N} \sum_{k=0}^{N-1} X_{k} e^{\frac{i 2 \pi k n}{N}}$

A very important application of the Fast Fourier Transform is the computation of a numerical approximation to the Fourier transform of function $f$ [9]. For this case a Fast Fourier transform is used to calculate all $X_{k}$ for the discrete Fourier transform, while Matlab was used as a mathematical instrument to find the components of the discrete Fourier transform of traffic functions (based on an FFT algorithm) [10].

The traffic function was defined for a given period of time (i.e. a day, a week or a month) and, at the moment of research, was created based on random numbers of vehicles/hour. After testing the proposed method a set of real values for the number of vehicles will be used to calibrate and tune the instrument.
This traffic function has three different shapes, selected to demonstrate the value of the method. These three shapes are: constant $(y(t))$, periodic $(z(t))$ and non-periodic $(v(t))$ (the last shape is obtained by mixing the periodic function with a random Gaussian noise).

The Fourier transform is calculated for all these three functions and the representations of the traffic functions in frequency domain are analysed.

The main interest is to find the image of the Fourier transform of a periodic traffic function in the image of a non-periodic function and to identify this periodic component.

\section{RESULTS}

Initially the three elementary traffic functions are analysed: constant, periodic and non-periodic (with periodic components). In the non-periodic function of traffic there is a periodic component. Using the Fourier transform, this component could be highlighted.

The main application of the method is to extract from an unpredictable traffic flow the main periodic component of the said traffic flow, which is revealed by the Fourier transform and its spectrum. The paper presents a traffic function which has two main components: one is the traffic function generated by public transport vehicles (buses), this function being considered as a periodic function, and the second one which is defined based on passenger vehicles and it is simulated using the function for the Gaussian random noise.

Based on instruments defined in the previous chapter the traffic function was analysed. The first step is to analyse the component of the function which is generated by public transport (buses) on a specific intersection.

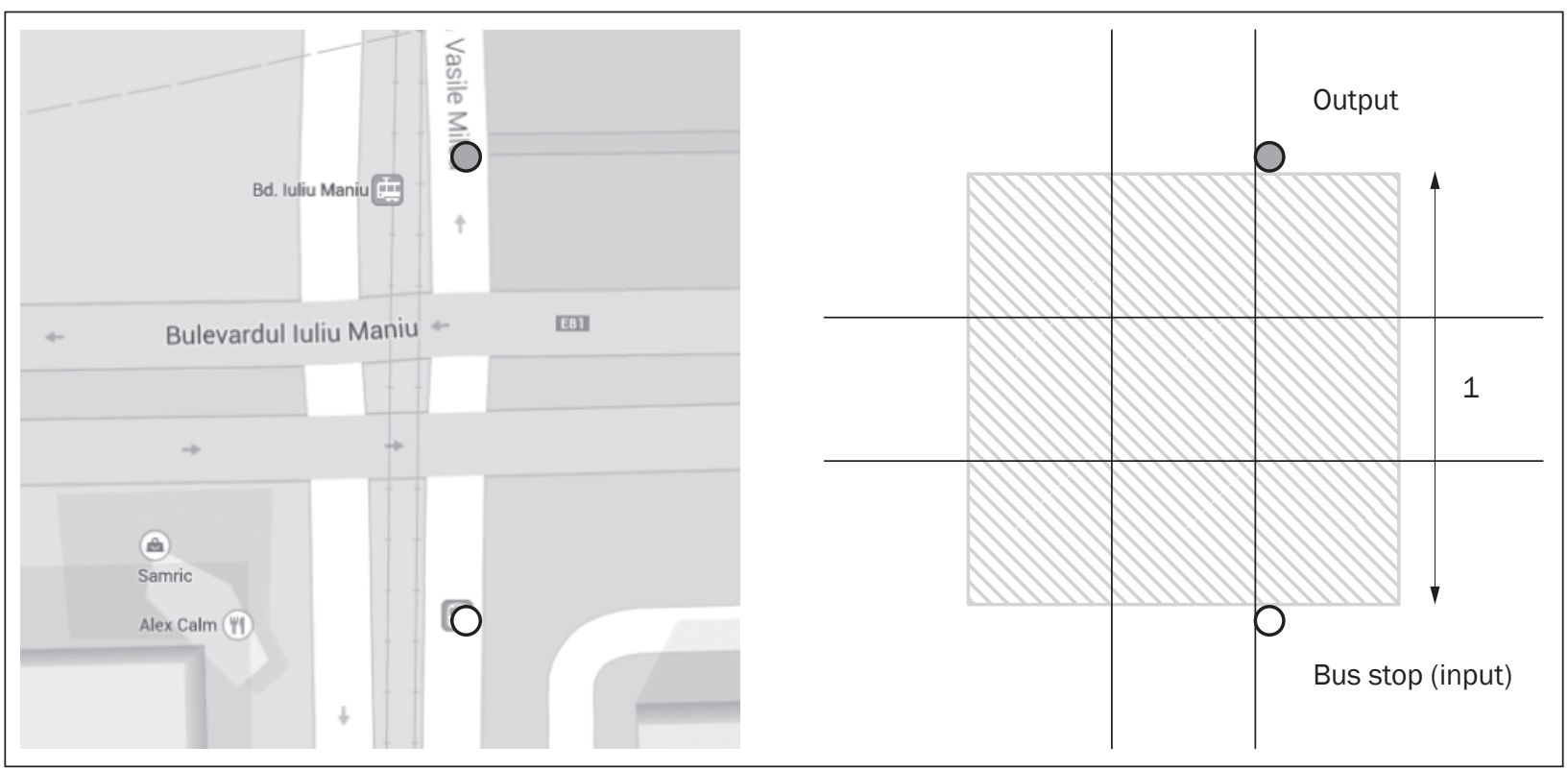

Figure 2 - The analysed intersection (intersection map based on Google map) 
For this case the buses are considered to generate a periodic component (based on a public transport time schedule) and every $T$ minutes (where $T$ is the period) two buses come and pass through the intersection; it means that the traffic function generated by buses is a pulse (as shown in Figure 2).

The specific selected area is situated on the inner ring road of Bucharest and the intersection is located on Iuliu Maniu Blvd. and Vasile Milea Street. Only bus line 105 was considered and the influence of this in total traffic of the intersection was underlined to demonstrate the functionality of the proposed method. The bus will enter the specific area after its stop (the bullet in lower part of the figure) and will exit this area in the the bullet drawn in upper part of the figure. The distance (noted with I in Figure 2) is passed by each bus in an average time of 27 seconds.

Another assumption is the equivalence of one bus with a number of passenger cars (PCE - Passenger Cars Equivalence); as such, the equivalent number of passenger cars is calculated based on the following formula [11]:

$P C E_{i j}=\frac{D_{i j}}{D_{\text {base }}}$

where:

$$
\begin{aligned}
P C E_{i j} & \text { PCE of vehicle type } i \text { under condition } j ; \\
D_{i j} & \text { average delay caused by vehicle type } i \\
& \text { under condition } j ; \\
D_{\text {base }}- & \text { average delay caused by one } \\
& \text { passenger car. }
\end{aligned}
$$

In case of this paper the input information was collected from Bucharest and the vehicles (the state of vehicles) and street infrastructure (the state of infrastructure) were considered as preliminary factors in defining the said conditions. For this reason $D_{b B}$ (type $i$ is $b$ from bus and the condition is $B$ from Bucharest) has a value equal to 27 seconds (the time needed for a bus to pass a specific area of an intersection). The delay $D_{\text {base }}$ for the same intersection is 5 seconds.

The expression (5) has the value:

$$
P C E_{b B}=\frac{D_{b B}}{D_{\text {base }}}=\frac{27}{5}=5.4
$$

A platoon of two buses was considered in the present case study; furthermore, the effect of the platoon on the traffic function on a specific intersection in a 0.5 hour time of monitoring is a pulse. The amplitude of this pulse is calculated based on the sum of PCEs from the two buses (the assumption is that the buses are the same and the effect on traffic function is the same for both buses considered). The PCE of the platoon is the sum of two PCEs, which means 10.8 (passenger car). The unit for collecting traffic data is five minutes and the result is 10.8 cars in five minutes. The traffic function for 30 minutes is presented in Figure 3 (where the shape is a rectangular pulse, and the Mat- lab function to generate this pulse is rectpuls).

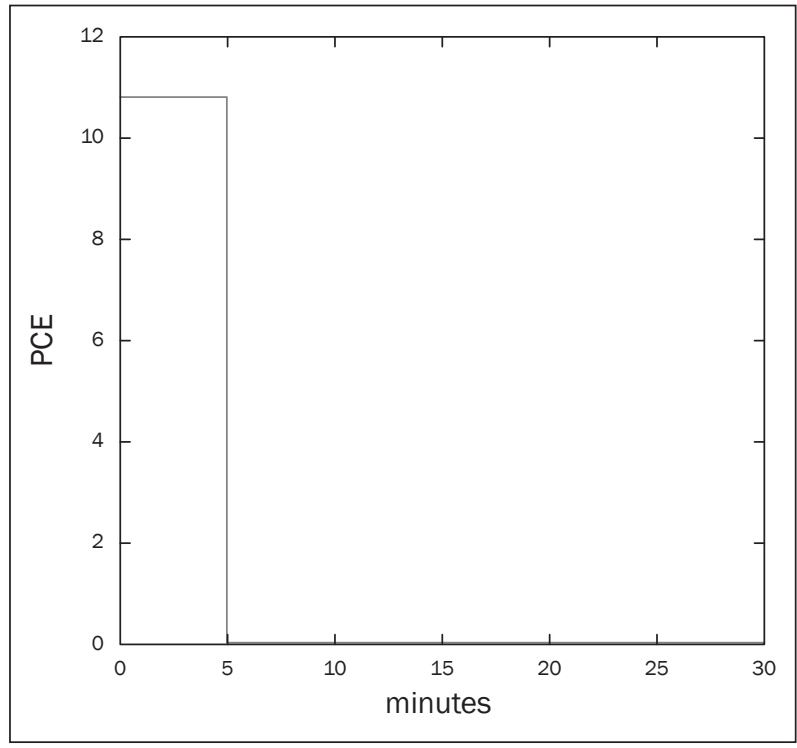

Figure 3 - Traffic function for two buses in 30 minutes time (monitoring unit is 5 minutes)

The traffic function from Figure 3 is defined as:

$f(t)=\left\{\begin{array}{c}2 \cdot P C E_{b B}=10.8 \text { for } t \in(0,5) \\ 0 \text { for } t \in(5,30)\end{array}\right.$

Based on definition (1) the Fourier transform for this function can be calculated as follows:

$F(w)=\int_{-\infty}^{+\infty} f(t) e^{-i \omega t} d t=\int_{0}^{5} 10.8 e^{-i \omega t} d t=$

$\frac{10.8}{j \omega}\left(1-e^{-i \omega 5}\right)=\frac{10.8}{j \omega}\left(e^{-i \omega \frac{5}{2}} e^{i \omega \frac{5}{2}}-e^{-i \omega \frac{5}{2}} e^{-i \omega \frac{5}{2}}\right)=$

$\frac{2 \cdot 10.8}{\omega} \cdot e^{-i \omega \frac{5}{2}}\left(\frac{e^{i \omega \frac{5}{2}}-e^{-i \omega \frac{5}{2}}}{2 j}\right)=$

$10.8 \cdot 5 \cdot \frac{\sin \frac{5 \omega}{2}}{\frac{5 \omega}{2}} \cdot e^{-i \omega \frac{5}{2}}=\left|10.8 \cdot 5 \cdot \frac{\sin \frac{5 \omega}{2}}{\frac{5 \omega}{2}}\right| \cdot e^{-i \omega \frac{5}{2}}=$

$\left|10.8 \cdot 5 \cdot \sin c \frac{5 \omega}{2}\right| \cdot e^{-i \omega \frac{5}{2}}$

where:

$\operatorname{sinc} x=\frac{\sin x}{x}$

Based on expression (8), the complex representation of traffic function in frequency domain could be decomposed into modulus and argument. Modulus is the amplitude of this representation (a cardinal sinus function, expression (9)) and the argument has in its composition a phase function. The shape of the modulus is presented in Figure 4. 


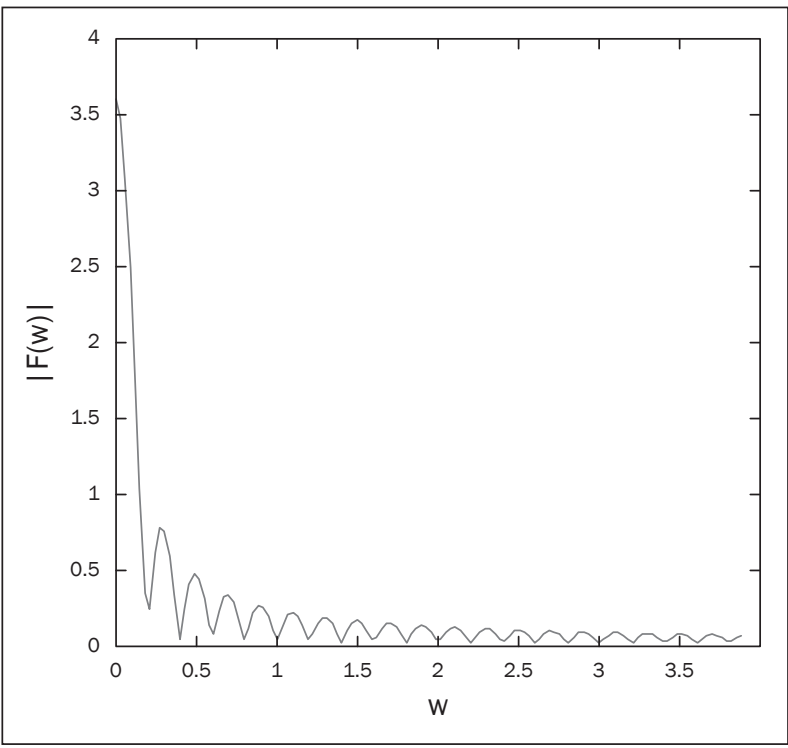

Figure 4 - Amplitude spectrum of traffic function $f(t)$

The amplitude spectrum presented in Figure 4 is the image of traffic function generated by a platoon of two buses in 30 minutes. If the time analysis is extended from 30 minutes to a full business day (18 hours) the traffic function will be changed from a rectangular pulse to a train of rectangular pulses. The traffic function is composed by 36 rectangular pulses based on the initial assumption that the schedule of public transport is uniformly distributed during a full business day (18 hours). In real cases, a full business day is decomposed in three or four sub-periods, in terms of time schedule and public transport vehicles allocation, and traffic function will be analysed in each sub-period defined.

The traffic function for public transport (buses) in a specific area of interest is defined (as shown in Figure 2) and the result is a sum of 36 rectangular pulses (one pulse for every two buses, every 30 minutes and 18 hours - 1,080 minutes - of public transport service of bus line 105).

The traffic function generated by the buses of bus line 105 in a specific area of Bucharest is shown in Figure 5 and it represents the result of adding 36 traffic functions for each 30 minutes of a business day in terms of public transport service.

Another important assumption is that the schedule is followed exactly by the bus drivers and the buses are uniformly distributed during one business day (as shown in Figure 5). Furthermore, a deviation from the timetable is permitted and the effect of this deviation was tested in terms of expanding the pattern of the function in frequency domain and of extracting it using different types of filters. For this purpose, two main modifications of the timetable were analysed: a systematic modification of bus frequency; the meaning of this is a modification of the period of traffic sub-function (a time delay is added to each period during the rush hour) and a specific modification of bus frequency, which means only few periods of traffic sub-functions were affected by modification (a time delay is added to some periods of traffic functions). A pattern of the traffic function representation in frequency could be drawn based on the real traffic function generated by a bus line and, based on this pattern, all traffic functions which are similar with this pattern could be extracted as functions generated by buses.

Using the said function the Fourier transform is calculated as follows:

$$
f(t)=f_{1}(t)+f_{2}(t)+\cdots+f_{n}(t)=\sum_{1}^{n} f_{i}(t)
$$

where:

$$
\begin{aligned}
& n-36 \text { (the number of intervals in one } \\
& \text { business day). }
\end{aligned}
$$

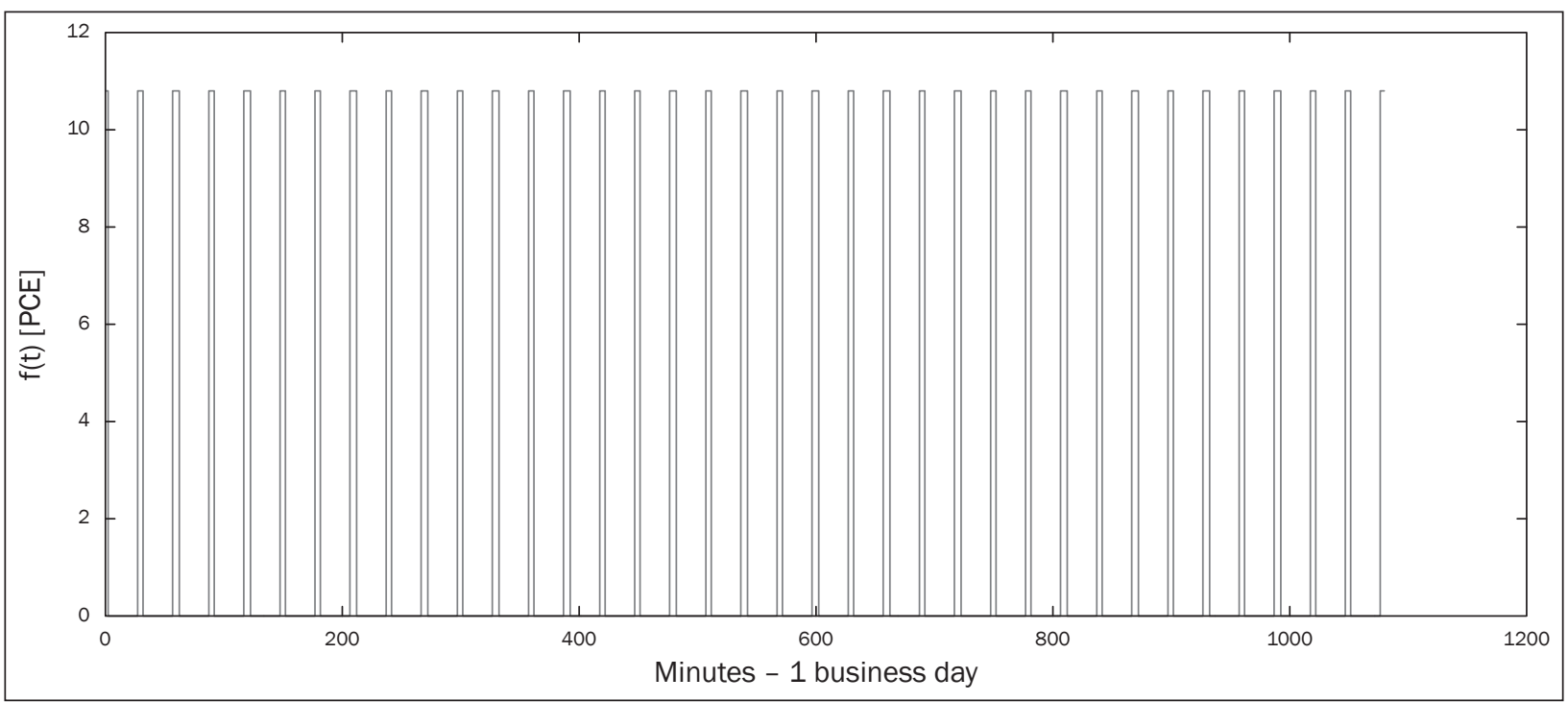

Figure 5 - Traffic function $f(t)$ for bus line 105 - one business day (1,080 minutes) 
Based on the properties of the Fourier transform, the transform of a function which is the sum of particular sub-functions is the sum of the transform of each particular sub-function.

$$
\begin{aligned}
& F\left\{\sum_{1}^{n} f_{i}(t)\right\}=F\left\{f_{1}(t)+f_{2}(t)+\cdots+f_{n}(t)\right\}= \\
& =F\left\{f_{1}(t)\right\}+F\left\{f_{2}(t)\right\}+\cdots+F\left\{f_{n}(t)\right\}=\sum_{1}^{n} F\left\{f_{i}(t)\right\}
\end{aligned}
$$

and

$$
\begin{aligned}
& f_{1}(t)=\left\{\begin{array}{l}
A \text { for } t \in(0, \tau) \\
0 \text { for } t \in(\tau, \infty)
\end{array}\right. \\
& f_{2}(t)= \begin{cases}A \text { for } t \in(T, T+\tau) \\
0 \text { for } t \notin(T, T+\tau)\end{cases} \\
& f_{n}(t)=\left\{\begin{array}{lll}
A \text { for } t \in((n-1) T,(n-1) T+\tau) \\
0 \text { for } t \notin((n-1) T,(n-1) T+\tau)
\end{array}\right.
\end{aligned}
$$

where:

$\tau$ - width of rectangular pulse (for this case 5 minutes);

$T$ - period of pulse repetition in this train of pulses (for this case 30 minutes);

$n$ - total number of periods in one day (36 in this case).

Based on expressions (8), (11), (12), (13) and (14) the Fourier transform of the traffic function $f(t)$, which is considered for a business day period has the following expression:

$F(\omega)=\left(1+e^{i \omega T}+e^{i 2 \omega T}+\ldots+e^{i(n-1) \omega T}\right) \cdot A \cdot \tau \operatorname{sinc}\left(\frac{\omega \tau}{2}\right) \cdot e^{-i \frac{\omega \tau}{2}}$

where:

$n-36$ (number of rectangular pulses);

$T-30$ minutes;

$\tau-5$ minutes.
Based on expression (15), the Fourier transform can be represented graphically as depicted in Figure 6 .

In Figure 6 the effect of the first rectangular pulse could be graphically recognised and its shape is the darkness part of the figure (the shape of cardinal sinus function). In this figure, the representation of traffic function in frequency domain is done and this is the image which is used to find the effect of the bus transport on general traffic function on a specific intersection.

To clearly present the problem in a readable manner, the traffic function was simplified (instead of 36 pulses, only 4 are selected) and the effect is presented in Figure 7. The main component of the representation in frequency domain of the simplified traffic function is marked with an arrow.

The next step in analysing the simplified traffic function was to mix this function with a Gaussian noise, which means other traffic functions which are not yet identified. This Gaussian noise function was added to the simplified traffic function and the result is a non-periodic traffic function (with some periodic components). Its graphical representation in time and frequency domain is shown in Figure 8.

In the representation of the Fourier transform a strong component is visible and the frequency is approx. $f=0.16 \mathrm{~Hz}$ (multiplied with $1 / 3,600$ seconds) that means the period $T=1 / f=6$ hours ( 4 times per 24 hours, which is the simplified traffic function considered in this case). This periodic component (as well as any other component) could be identified in the frequency representation of the non-periodic traffic function and a decomposition of this complex traffic function is possible for further analyses.

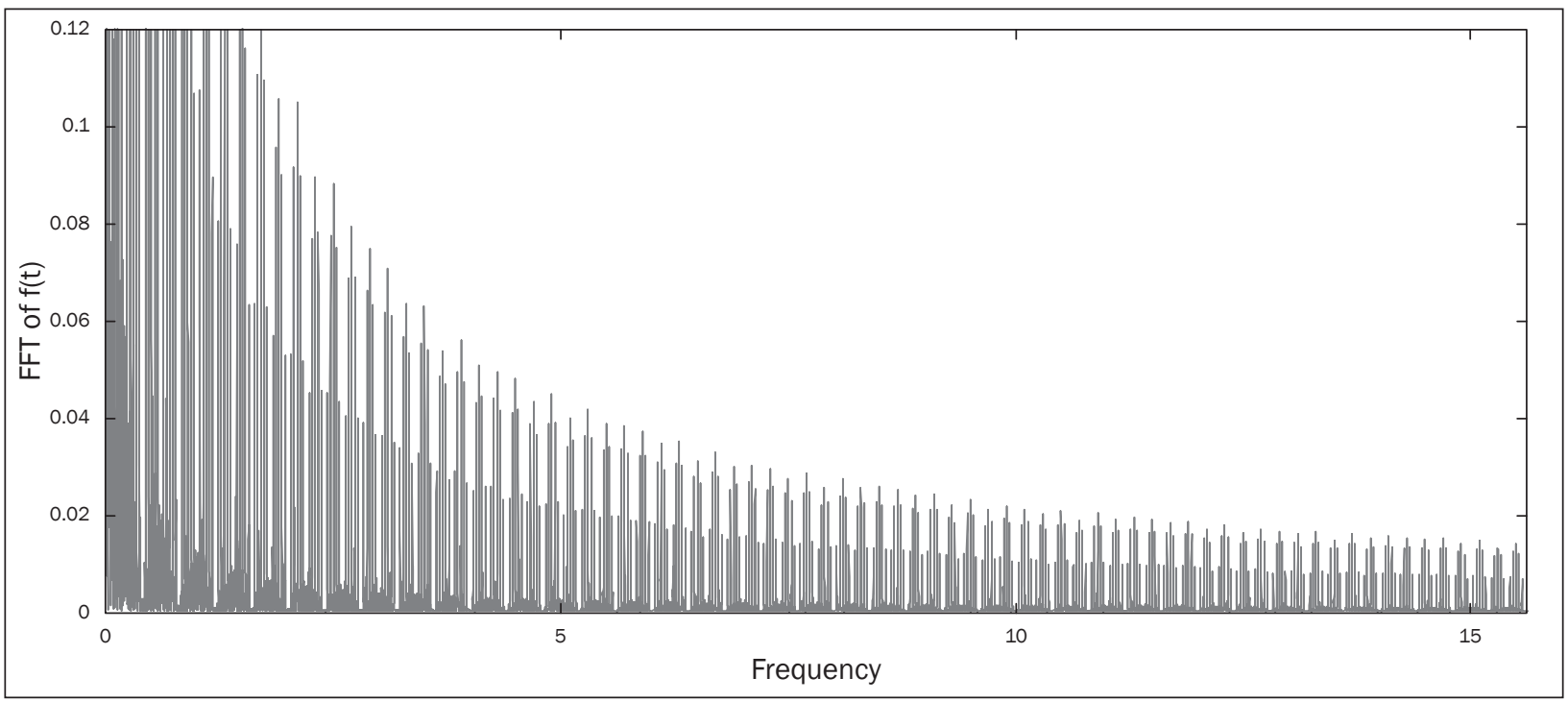

Figure 6 - FFT of traffic function for one business day 


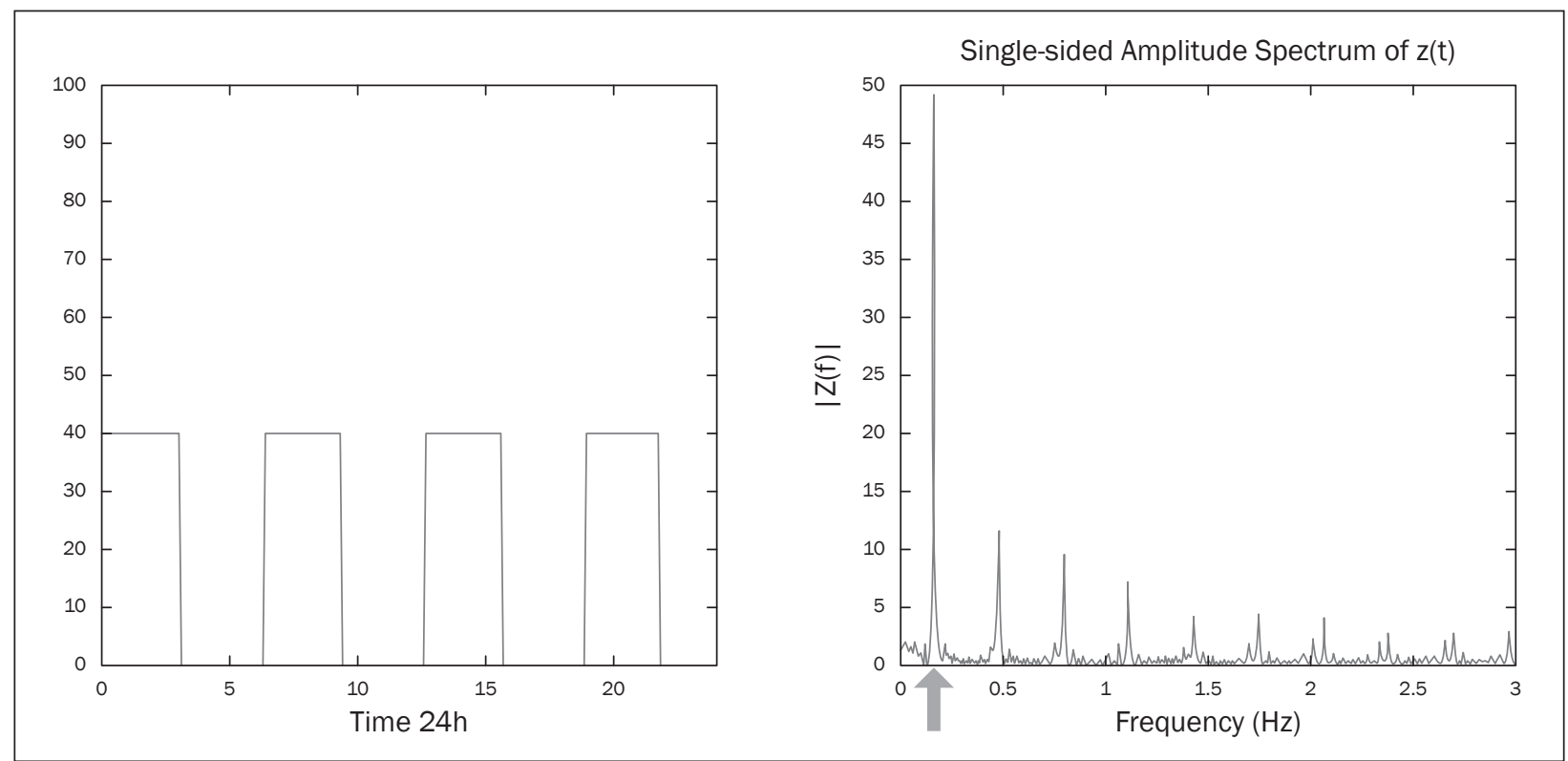

Figure 7 - Periodic traffic function and its Fourier transform

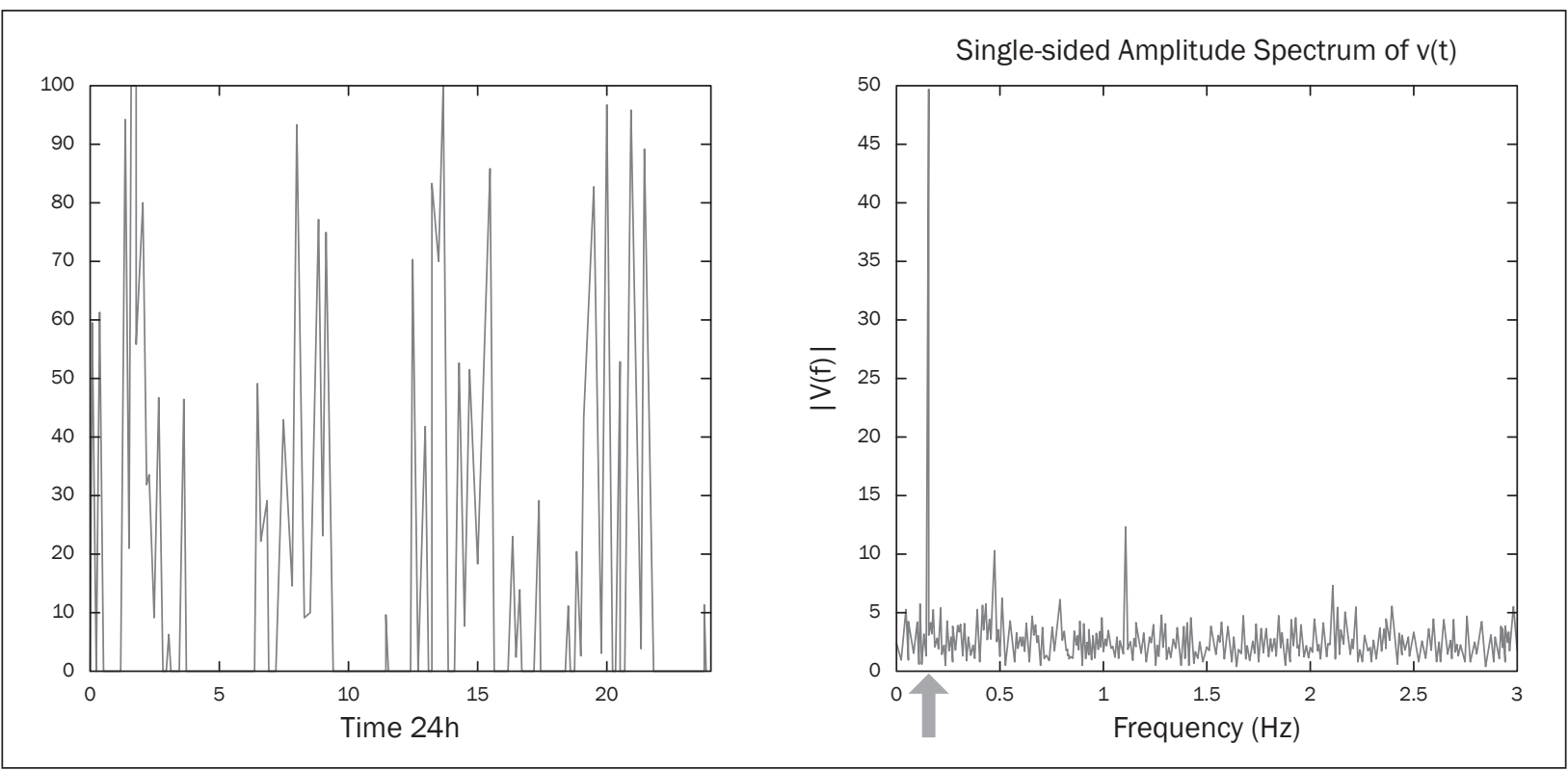

Figure 8 - Non periodic traffic function and its Fourier transform

\section{EXTENSIONS OF THE RESEARCH}

At this moment the results allow extraction of the periodic component of traffic functions as well as any other important component from the frequency representation of the function (based on FFT representation and its frequency image). The main research focus is the definition of traffic function in time and to represent this traffic function in frequency. Based on this, an analysis of traffic sub-functions was done. The method permits the extraction of some periodic components, such as public transport, as well as the identifying the modification of public transport schedule. By present research the following hypothesis is verified: the bus traffic, as a periodical traffic function, could be extracted from the general traffic function.

An extension of this research, which is tested now in the laboratory, relates to use of the Fourier analysis to improve the results of predictive traffic control. Based on this transform, a solution is revealed to identify and extract the main components of the traffic function for an intersection, a group of intersections or an urban area, and to split the components of traffic function into two categories: periodic (which is simple and predictable and very simple to be implemented in a predictive algorithm) and random (which is very complicated in terms of being implemented in a predictive algorithm). 


\section{CONCLUSIONS}

The traffic function is a function which is generated by different sources (cars, buses, bikes etc.) and an indepth analysis of said function could offer new ways of solving traffic problem in urban areas. The analysis of aforementioned traffic function could be initiated from the function itself (the approach of the author in [4]) or from the sub-functions, which are the components of the function (i.e. the current approach in present research). The traffic function could be defined as a sum of particular traffic sub-functions, which have a representation in time domain as well as a representation in frequency domain. In the example of the analysed intersection, a bus line generates a sub-function for the traffic function associated with this intersection and each category of vehicles as main sources of traffic sub-functions generates various sub-functions, which can be added to the main traffic function.

The main research idea presented in this paper is to use the Fourier transform (FFT version for computer base analysis) for the decomposition of traffic functions in their main components (in terms of sources of traffic flow) and for identifying and extracting the said components from the traffic function (in this paper the focus is on public transport - a bus line - influence on the traffic function, yet this analysis could be extended to other vehicles, while the typology of traffic sources has to be defined). The general traffic function is a composed function, while different traffic participants add a quantity to this function, which is called sub-function. Based on the Fourier analysis, these quantities (as partial traffic functions or sub-function) could be identified and extracted from the main function.

The research presented in the paper shows an important issue related to the traffic function, that is, its components are not precisely periodic function, that means a deviation (a time delay) is accepted and the result of the analysis is in line with the case of pure periodic functions.

The method presented in the paper could be used and applied to improve the existing solutions for traffic control and management applications, especially for predictive traffic control where the components of traffic flow could be decomposed and defined and the control system could extract the main sub-functions based on this type of analysis. The mathematical tool is based on FFT (Fast Fourier Transform) algorithm and the extension of the research could include other transforms and algorithms.

FLORIN NEMTANU, doctor

E-mail: florin.nemtanu@upb.ro

ILONA COSTEA, doctor

E-mail: ilona.costea@upb.ro

CATALIN DUMITRESCU, doctor

E-mail: catalincatalin9@gmail.com

Universitatea POLITEHNICA din Bucuresti

Facultatea Transporturi,

Departamentul Telecomenzi si Electronica in Transporturi Splaiul Independentei nr. 313, 060042, Bucuresti, Romania

\section{ANALIZA SPECTRALA A FUNCTIILOR DE TRAFIC IN ZONELE URBANE}

\section{ABSTRACT}

Lucrarea este orientate catre aplicarea Transformatei Fourier in analiza traficului urban si utilizarea acestei transformate in descompunerea traficului. Functia de traffic este definite ca fiind fluxul de trafic generat de diferitele categorii de participant la trafic. $O$ analiza Fourier a fost elaborate pentru a identifica principalele componente ale asa numitei functii de trafic, numite sub-functii de trafic. Lucrarea prezinta rezultatele aplicarii metodei intr-o situatie reala, respective o intersectie din Bucuresti unde au fost analizate efecetele unei linii de autobuz. Analiza a fost efectuata folosind diferite unitati de timp sit rei functii de traffic au fost definite pentru a demonstra avantajele metodei propuse. Este propusa si o extindere a metodei aplicata pentru zonele urbane care sunt acoperite de sisteme de control adaptive al traficului.

\section{CUVINTE CHEIE}

Fluxuri de traffic; analiza Fourier; controlul traficului urban; componentele traficului;

\section{REFERENCES}

[1] $\mathrm{Hu}$ Y, Hellendoorn J. Uncertainty modeling for urban traffic model predictive control based on urban patterns. 16th International IEEE Conference on Intelligent Transportation Systems - (ITSC); 2013.

[2] Xu Y, Kong QJ, Lin S, Liu Y. Urban traffic flow prediction based on road network model. 9th IEEE International Conference on Networking Sensing and Control (ICNSC); 2012.

[3] Ye Z, Guoqiang C, Limin J, Min G, Xiaoqing C. Modeling and Application of Urban Dynamic Region Traffic Model Based on Information Fusion. 4th International Conference on Networked Computing and Advanced Information Management NCM '08; 2008.

[4] Dendrinos DS. Urban Traffic Flows and Fourier Transforms. J Geographical Analysis. 1994;26(3):261-281.

[5] Prikryl J. Simple model for urban traffic between two signalized intersections. 16th International IEEE Conference on Intelligent Transportation Systems - (ITSC); 2013.

[6] MathWorks Documentation. MathWorks. [Internet]. [cited 10 October 2014]. Available from: http://www. mathworks.com/help/index.html.

[7] Dyke P. An Introduction to Laplace Transforms and Fourier Series. London: Springer Verlag; 1999.

[8] Kammler DW. A First Course in Fourier Analysis. New York: Cambridge University Press; 2007.

[9] Boggess A, Narcowich F. A First Course in Wavelets with Fourier Analysis. New Jersey: John Wiley \& Sons; 2009.

[10] FFTW. [Internet]. [cited 10 October 2014]. Available from: http://www.fftw.org/.

[11] Chitturi MV. Methodology for Development of Delay-based Passenger Car Equivalents of Heavy Vehicles in Work Zones [study]. Urbana Illionos: University of Illinois at Urbana; 2002. 